\title{
New genus-specific primers for the PCR identification of members of the genera Pseudonocardia and Saccharopolyspora
}

\author{
Raquel Morón, Ignacio González and Olga Genilloud
}

\author{
Author for correspondence: Olga Genilloud. Tel: +34913210 568. Fax: +34913210614 \\ e-mail: olga_genilloud@merck.com
}

Centro de Investigación Básica de España, Merck Sharp and Dohme Research Laboratories, Josefa Valcárcel 38, 28027 Madrid, Spain

\begin{abstract}
Members of the family Pseudonocardiaceae are difficult to identify on the basis of their micromorphology only. The biochemical characterization of each new isolate is a painstaking and time-consuming task which cannot always be undertaken when handling large numbers of strains as is the case in natural product screening programmes. In this study, two sets of genus-specific oligonucleotides were designed which allow rapid detection of members of the genera Pseudonocardia and Saccharopolyspora by means of PCR-specific amplification. The genus specificity of these primers was validated on a wide range of collection strains and the primers were subsequently used to study a group of 106 wild-type isolates that possessed morphological characteristics of the family. Out of this group, 51 strains could be identified as members of the genus Pseudonocardia and only nine isolates could be assigned to the genus Saccharopolyspora. The diversity indicated by whole-cell fatty acid profiles of both wild-type and reference strains was compared with that identified using the oligonucleotide primers. The partial 16S rDNA sequencing of representative wild-type strains was used to validate their genus assignment by PCR-specific amplification. This study shows the industrial usefulness of the application of these direct identification tools as well as the complementary use of two sources of data, PCR-specific amplification results and fatty acid composition, to assess the diversity of a microbial population.
\end{abstract}

Keywords: Pseudonocardiaceae, $\mathrm{PCR}$ primers, 16S rDNA sequences

\section{INTRODUCTION}

Historically, natural product screening programs have focussed on the order Actinomycetales, one of the most intensively isolated groups of micro-organisms which, through the years, has efficiently demonstrated its ability to produce a large diversity of new secondary metabolites (Sanglier et al., 1993). Besides the genus Streptomyces, which has been extensively exploited, members of other genera are also considered of high interest as potential producers of novel bioactive compounds. However, no specific procedures are normally available for the direct and specific isolation of cultures belonging to these groups. In addition, the wide range of morphologies and phenotypes found

Abbreviations: FAMEs, fatty acid methyl esters; $T_{m}$, melting temperature. The GenBank accession numbers for the sequences reported in this paper are AF061976, AF061977 and AF064968-AF064983. within strains of the same genus, together with the frequent absence of sporulation characteristics, sometimes hinder an initial rapid and reliable morphological identification during routine isolation.

This is the case with the family Pseudonocardiaceae, the subject of this study, which includes species that are very well-known producers of the antibiotics erythromycin, vancomycin or rifamycins (Embley, 1992). Initially, this group of actinomycetes contained strains which had the absence of mycolic acids and cell wall chemotype IV (meso-diaminopimelic acid, arabinose and galactose) as main chemotaxonomic markers; they were only described as a family in 1988 after phylogenetic analysis (Embley et al., 1988a, b). This family then comprised the genera Actinopolyspora, Amycolatopsis, Kibdelosporangium, Pseudonocardia, Saccharomonospora and Saccharopolyspora. The former genera Amycolata and Pseudonocardia have been recently combined in the emended genus 
R. Morón, I. González and O. Genilloud

Table 1. Reference strains used in this study and results obtained from selective PCR amplification

\begin{tabular}{|c|c|c|c|c|}
\hline \multirow[t]{2}{*}{ Species } & \multirow[t]{2}{*}{ Strain designation } & \multicolumn{2}{|c|}{ Amplification results* } & \multirow[t]{2}{*}{ FAME analysis $\dagger$} \\
\hline & & AMP3/AMP2 & SP1/SP3 & \\
\hline \multicolumn{5}{|l|}{ Pseudonocardiaceae } \\
\hline \multicolumn{5}{|l|}{ Actinopolyspora: } \\
\hline Actinopolyspora thermovinacea & ATCC 35862 & 0 & 0 & + \\
\hline \multicolumn{5}{|l|}{ Amycolatopsis: } \\
\hline Amycolatopsis azurea & DSM $43854^{\mathrm{T}}$ & 0 & 0 & + \\
\hline Amycolatopsis fastidiosa & ATCC $31181^{\mathrm{T}}$ & 0 & 0 & + \\
\hline Amycolatopsis mediterranei & ATCC $13685^{\mathrm{T}}$ & 0 & 0 & \\
\hline Amycolatopsis methanolica & NCIB $11946^{\mathrm{T}}$ & 0 & 0 & + \\
\hline Amycolatopsis orientalis & NRRL 18098 & 0 & 0 & + \\
\hline Amycolatopsis orientalis & NRRL 18099 & 0 & 0 & + \\
\hline Amycolatopsis orientalis & NRRL 18100 & 0 & 0 & + \\
\hline Amycolatopsis orientalis subsp. orientalis & NRRL 2452 & 0 & 0 & + \\
\hline Amycolatopsis orientalis subsp. orientalis & ATCC 21425 & 0 & 0 & + \\
\hline Amycolatopsis orientalis subsp. orientalis & DSM $40040^{\mathrm{T}}$ & 0 & 0 & + \\
\hline Amycolatopsis rugosa & ATCC $43014^{\mathrm{T}}$ & 0 & 0 & \\
\hline Amycolatopsis sulphurea & NRRL $2822^{\mathrm{T}}$ & 0 & 0 & + \\
\hline \multicolumn{5}{|l|}{ Kibdelosporangium: } \\
\hline Kibdelosporangium aridum subsp. aridum & ATCC $39323^{\mathrm{T}}$ & 0 & 0 & \\
\hline Kibdelosporangium aridum subsp. largum & ATCC $39922^{\mathrm{T}}$ & 0 & 0 & \\
\hline \multicolumn{5}{|l|}{ Pseudonocardia: } \\
\hline Pseudonocardia autotrophica & ATCC $19727^{\mathrm{T}}$ & 0 & 1 & + \\
\hline Pseudonocardia autotrophica & DSM 43103 & 0 & 1 & \\
\hline Pseudonocardia autotrophica & DSM 43098 & 0 & 1 & + \\
\hline Pseudonocardia compacta & ATCC $35407^{\mathrm{T}}$ & 0 & 1 & + \\
\hline Pseudonocardia halophobica & DSM $43089^{\mathrm{T}}$ & 0 & 1 & + \\
\hline Pseudonocardia hydrocarbonoxydans & NRRL B-16171 ${ }^{\mathrm{T}}$ & 0 & 1 & + \\
\hline 'Pseudonocardia nitrificans' & DSM 46012 & 0 & 1 & + \\
\hline Pseudonocardia petroleophila & DSM $43193^{\mathrm{T}}$ & 0 & 1 & + \\
\hline Pseudonocardia saturnea & NRRL B-16172 & 0 & 1 & + \\
\hline Pseudonocardia thermophila & ATCC $19285^{\mathrm{T}}$ & 0 & 1 & + \\
\hline \multicolumn{5}{|l|}{ Saccharomonospora: } \\
\hline Saccharomonospora azurea & ATCC $43670^{\mathrm{T}}$ & 0 & 0 & + \\
\hline 'Saccharomonospora caesia' & ATCC 49227 & 0 & 0 & + \\
\hline Saccharomonospora cyanea & ATCC $43724^{\mathrm{T}}$ & 0 & 0 & + \\
\hline Saccharomonospora glauca & DSM $43769^{\mathrm{T}}$ & 0 & 0 & \\
\hline Saccharomonospora internatus & $\operatorname{ATCC} 33517^{\mathrm{T}}$ & 0 & 0 & \\
\hline Saccharomonospora viridis & ATCC 15345 & 0 & 0 & + \\
\hline Saccharomonospora viridis & ATCC $15386^{\mathrm{T}}$ & 0 & 0 & \\
\hline \multicolumn{5}{|l|}{ Saccharopolyspora: } \\
\hline Saccharopolyspora erythraea & NRRL $2338^{\mathrm{T}}$ & 1 & 0 & + \\
\hline Saccharopolyspora gregorii & NCIB $12823^{\mathrm{T}}$ & 1 & 0 & + \\
\hline Saccharopolyspora hirsuta subsp. hirsuta & ATCC 27876 & 1 & 0 & + \\
\hline Saccharopolyspora hirsuta subsp. hirsuta & NRRL B5792 ${ }^{\mathrm{T}}$ & 1 & 0 & + \\
\hline Saccharopolyspora hirsuta subsp. kobensis & ATCC $20501^{\mathrm{T}}$ & 1 & 0 & + \\
\hline Saccharopolyspora hordei & NCIB $12824^{\mathrm{T}}$ & 1 & 0 & + \\
\hline Saccharopolyspora rectivirgula & ATCC 15347 & 1 & 0 & \\
\hline Saccharopolyspora rectivirgula & ATCC $33515^{\mathrm{T}}$ & 1 & 0 & \\
\hline Saccharopolyspora spinosa & NRRL 18537 & 1 & 0 & + \\
\hline Saccharopolyspora spinosa & ATCC $49460^{\mathrm{T}}$ & 1 & 0 & \\
\hline Saccharopolyspora taberi & NRRL $16173^{T}$ & 1 & 0 & + \\
\hline \multicolumn{5}{|l|}{ Saccharothrix: } \\
\hline Saccharothrix aerocolonigenes & ATCC 39243 & 0 & 0 & + \\
\hline
\end{tabular}


Table 1 (cont.)

\begin{tabular}{|c|c|c|c|c|}
\hline \multirow[t]{2}{*}{ Species } & \multirow[t]{2}{*}{ Strain designation } & \multicolumn{2}{|c|}{ Amplification results* } & \multirow[t]{2}{*}{ FAME analysis $\dagger$} \\
\hline & & AMP3/AMP2 & SP1/SP3 & \\
\hline Saccharothrix cryophilis & NRRL B-16238 & 0 & 0 & \\
\hline Saccharothrix flava & DSM $43885^{\mathrm{T}}$ & 0 & 0 & + \\
\hline Saccharothrix mutabilis subsp. mutabilis & DSM $43853^{\mathrm{T}}$ & 0 & 0 & + \\
\hline Saccharothrix syringae & DSM $43886^{\mathrm{T}}$ & 0 & 0 & + \\
\hline Saccharothrix waywayandensis & NRRL B-16159T & 0 & 0 & + \\
\hline \multicolumn{5}{|l|}{ Actinokineospora: } \\
\hline Actinokineospora riparia & NRRL B-16433 ${ }^{\mathrm{T}}$ & 0 & 0 & \\
\hline \multicolumn{5}{|l|}{ Other genera } \\
\hline Kitasatosporia setalba & ATCC $33774^{\mathrm{T}}$ & 0 & 0 & \\
\hline Micromonospora echinospora subsp. pallida & NRRL $2996^{\mathrm{T}}$ & 0 & 0 & \\
\hline Streptomyces avermitilis & ATCC 31267 & 0 & 0 & \\
\hline Streptomyces cattleya & NRRL 8057 & 0 & 0 & \\
\hline Streptomyces hygroscopicus subsp. ascomyceticus & MA 6572 & 0 & 0 & \\
\hline Streptomyces hygroscopicus subsp. hygroscopicus & ATCC $27438^{\mathrm{T}}$ & 0 & 0 & \\
\hline Streptomyces hygroscopicus subsp. rapamyceticus & NRRL 5491 & 0 & 0 & \\
\hline Streptomyces sp. & - & 0 & 0 & \\
\hline Streptomyces tsukubaensis & MA 6492 & 0 & 0 & \\
\hline Streptoverticillium sp. & - & 0 & 0 & \\
\hline
\end{tabular}

*Amplification results with primers AMP3/AMP2 and SP1/SP3; '1' represents a band of the expected size (640 or 371 bp, respectively) and ' 0 ' represents the absence of amplification products.

† Strains whose fatty acid profiles were included in Fig. 3 are indicated by ' + '.

Pseudonocardia (Warwick et al., 1994). The importance of the presence of arabinose as a chemotaxonomic marker for Pseudonocardiaceae has been intensively discussed, given the close phylogenetic relationship found between members of this family and the genera Saccharothrix, Kutzneria and Actinosynnema, as well as the recently described genus Thermocrispum (Takeuchi et al., 1992; Embley \& Stackebrandt, 1994; Korn-Wendisch et al., 1995), which show cell wall chemotype III rather than chemotype IV and contain rhamnose instead of arabinose. These genera, together with the genus Actinokineospora, which shows cell wall chemotype IV but is closely related to the genus Saccharothrix (Stackebrandt et al., 1994; Warwick et al., 1994; Yassin et al., 1995), have remained outside the family until recently. The last proposal for a new classification system of the order Actinomycetales, based on the phylogenetic relationships established from a $16 \mathrm{~S}$ rDNA-RNA sequence analysis, includes all these genera within the family Pseudonocardiaceae with the exception of the genus Actinokineospora (Stackebrandt et al., 1997).

An alternative approach to the traditional isolation and identification methods of members of this family of Actinomycetales should consider not only the need for a better knowledge of their distribution and dependence on the environmental conditions, but the development of new identification techniques based on precise genotypic information that is not influenced by cultivation conditions. Frequently, classical methods have failed to describe completely the natural composition of certain microbial communities from which only the cultivatable micro-organisms can be identified (McVeigh et al., 1996). Recent advances in nucleic acid techniques, based on data derived from the comparative analysis of the $16 \mathrm{~S}$ rRNA sequences, have allowed the development of new and powerful tools that can be applied to the study of micro-organisms (Fox \& Stackebrandt, 1987; Ludwig \& Schleifer, 1994). In addition to the phylogenetic analyses derived from the study of the 16S rRNA molecule, the great variation in the regional sequence conservation of this molecule can also be exploited as a reliable tool to develop specific probes that can be applied at different taxonomic levels (Stackebrandt et al., 1991; Stahl \& Amann, 1991; McVeigh et al., 1995). The use of specific probes as selective amplification primers offers an alternative approach for the rapid identification of large numbers of strains (Mehling et al., 1995; Yoon et 
Table 2. Wild-type isolates used in this study

Genus designations of strains were established according to PCR amplification data.

\begin{tabular}{|c|c|c|}
\hline Strain & Country & Source \\
\hline \multicolumn{3}{|l|}{ Saccharopolyspora spp. } \\
\hline $\mathrm{E} 10^{*}$ & Bolivia & Soil \\
\hline $\mathrm{C} 21^{*}$ & Brazil & Tropical rain forest soil \\
\hline G3 & India & Deciduous forest soil \\
\hline $\mathrm{H} 3^{*}$ & Madagascar & Soil \\
\hline $\mathrm{E} 20^{*}$ & Puerto Rico & Decomposing plant material \\
\hline H18 & Sri Lanka & Soil \\
\hline A15* & Taiwan & Soil \\
\hline $\mathrm{H} 11, \mathrm{H} 13$ & West Indies & Decomposing plant material \\
\hline \multicolumn{3}{|l|}{ Amycolatopsis spp. } \\
\hline B08, EO3 & Brazil & Soil \\
\hline $\mathrm{C} 18$ & Costa Rica & Sawdust \\
\hline $\mathrm{H} 4$ & Costa Rica & Organic material \\
\hline G11 & India & Decomposing plant material \\
\hline E15 & Panama & Tropical rain forest soil \\
\hline G22 & Panama & Mangrove mud \\
\hline $\mathrm{G} 2, \mathrm{H} 16$ & Spain & Soil \\
\hline G1, G18, G20, G21 & Canary Islands, Spain & Soil \\
\hline $\mathrm{C} 02$ & Venezuela & Soil \\
\hline \multicolumn{3}{|l|}{ Pseudonocardia spp. } \\
\hline B07 & Brazil & Soil \\
\hline A09 & Costa Rica & Plant material \\
\hline B04, B09, E09 & Costa Rica & Soil \\
\hline E07, E11 & Costa Rica & Decomposing plant material \\
\hline $\mathrm{A} 04, \mathrm{~A} 05^{*}, \mathrm{~A} 06, \mathrm{~B} 03, \mathrm{~B} 05$ & Costa Rica & Sawdust \\
\hline $\mathrm{A} 01, \mathrm{~B} 11, \mathrm{D} 17, \mathrm{H} 17$ & India & Semiarid soil \\
\hline $\mathrm{C} 10, \mathrm{E} 08$ & India & Dense tropical rain forest soil \\
\hline $\mathrm{A} 03, \mathrm{D} 01, \mathrm{D} 02, \mathrm{D} 07, \mathrm{D} 08, \mathrm{D} 14$ & India & Rain forest soil \\
\hline B01, D11*, D12 & India & Desert soil \\
\hline $\mathrm{A} 12^{*}, \mathrm{G} 5, \mathrm{G} 6, \mathrm{G} 7 *, \mathrm{G} 13, \mathrm{G} 14$ & India & Decomposing plant material \\
\hline $\mathrm{H} 9^{*}$ & India & Plant material \\
\hline $\mathrm{C} 05, \mathrm{C} 06, \mathrm{C} 17$ & Mexico & Volcanic soil \\
\hline D15 & Mexico & Soil \\
\hline $\mathrm{O} 1^{*}, \mathrm{G} 23$ & Panama & Tropical rain forest soil \\
\hline $\mathrm{C} 07$ & The Philippines & Soil \\
\hline A16, E16, E19 & Puerto Rico & Decomposing plant material \\
\hline $\mathrm{A} 02, \mathrm{~A} 14, \mathrm{D} 16$ & Sri Lanka & Soil \\
\hline E13 & Taiwan & Rice field soil \\
\hline $\mathrm{H} 8$ & Taiwan & Soil \\
\hline $\mathrm{H} 2$ & Venezuela & Soil \\
\hline $\mathrm{H} 10$ & Costa Rica & Decomposing plant material \\
\hline \multicolumn{3}{|l|}{ Non-identified actinomycetes } \\
\hline A10 & Costa Rica & Plant material \\
\hline $\mathrm{C} 11$ & Costa Rica & Soil \\
\hline $\mathrm{A} 07, \mathrm{~A} 08, \mathrm{G} 3, \mathrm{G} 4$ & Costa Rica & Sawdust \\
\hline $\mathrm{B} 12, \mathrm{D} 03$ & India & Tropical rain forest soil \\
\hline $\mathrm{C} 03$ & India & Semitropical forest soil \\
\hline $\mathrm{C} 01, \mathrm{C} 12$ & India & Soil \\
\hline $\mathrm{HH} 01$ & India & Arid soil \\
\hline E12 & India & Decomposing plant material \\
\hline $\mathrm{C} 04$ & Mexico & Volcanic soil \\
\hline H14, H15 & Philippines & Soil \\
\hline $\mathrm{C} 19$ & Puerto Rico & Decomposing plant material \\
\hline
\end{tabular}


Table 2 (cont.)

\begin{tabular}{|lll|}
\hline Strain & \multicolumn{1}{c|}{ Country } & Source \\
\hline G8, G10 & Taiwan & Garden soil \\
H7 & Taiwan & Soil \\
H5, H6 & Uganda & Soil \\
HHO2 & Costa Rica & Sawdust \\
D18 & Spain & Altitude forest soil \\
E14, G15, G16, G17, G19 & Canary Islands, Spain & Soil \\
HH03, HH15 & Spain & Soil \\
G9 & Taiwan & Rice field soil \\
\hline
\end{tabular}

* Strains selected to be partially sequenced.

al., 1996). Species-specific probes have already been described for a large number of clinically relevant micro-organisms, but in this case, their application is restricted to identification at the species level. This study is focussed on the search for genus-specific probes that could potentially be applied to the detection and molecular identification of diverse strains belonging to the same genus. The development of new tools that can be used to study the family Pseudonocardiaceae is presented. Two sets of genus-specific oligonucleotides have been designed that are specific for the genera Pseudonocardia and Saccharopolyspora based on the comparative analysis of their 16S rRNA. These pairs of oligonucleotides allow a one-step identification of all strains belonging to these genera by means of selective amplification of partially purified genomic DNA.

\section{METHODS}

Bacterial strains. The bacterial strains used as reference organisms in this study are listed in Table 1 . The 106 soil actinomycetes (wild-type isolates) included in this study were obtained from the laboratory culture collection. These strains were isolated from soils and plant materials obtained from diverse geographic origins (Table 2). All strains were grown on YMG $(0.4 \%$ glucose, $0.4 \%$ yeast extract and $1.0 \%$ malt extract) agar and brain/heart agar (Difco) at $28^{\circ} \mathrm{C}$ except for thermophilic strains, which were grown at $50{ }^{\circ} \mathrm{C}$.

Design of oligonucleotide primers. Sequence comparison and analysis were carried out using programs from the University of Wisconsin GCG package (version 7.2, September 1994). The following 16S rRNA-DNA sequences, obtained from GenBank/EMBL, were studied for the design of the primers: X76953, Actinokineospora riparia (IFO 14541); X54287, Actinopolyspora halophila (ATCC 279); Z22730, Actinopolyspora mortivallis (JCM 7550); X76954, Amycolata alni (Ac901); X54288, Amycolata autotrophica (DSM 43210 $)$; X76955, Amycolata hydrocarbonoxydans (DSM 43281 ); X55609, 'Amycolata nitrificans' (DSM, IFAM 379); X55608, Amycolata petroleophila(DSM, IFAM $\left.78^{\mathrm{T}}\right)$; X76956, Amycolata saturnea (DSM 43195'); X53199, Amycolatopsis azurea (NRRL 11412 ${ }^{\mathrm{T}}$; X53200, Amyco- latopsis fastidiosa (ATCC $31181^{\mathrm{T}}$ ); X76957, Amycolatopsis mediterranei (DSM 13685 ${ }^{\mathrm{T}}$ ); X54274, Amycolatopsis methanolica (NCIB 11946 ${ }^{\mathrm{T}}$ ); X81573, Amycolatopsis orientalis (DSM 43187); X76958, Amycolatopsis orientalis subsp. orientalis (DSM 40040 $)$; X53191, Kibdelosporangium aridum (ATCC 39323 $)$; X76959, Pseudonocardia compacta (DSM 43592 ${ }^{\mathrm{T}}$; Z14111, Pseudonocardia halophobica (DSM 43089 ${ }^{\mathrm{T}}$ ); X53195, Pseudonocardia thermophila (ATCC $19285^{\mathrm{T}}$ ); X76960, 'Saccharomonospora caesia' (INMI $19125^{\mathrm{T}}$ ); X54286, Saccharomonospora viridis (ATCC $15386^{\mathrm{T}}$ ); X76961, Saccharomonospora sp. (A1206); X53198, Saccharopolyspora erythraea (NRRL 2338 ); X76962, Saccharopolyspora gregorii (NCIB 12823 $)$; X53196, Saccharopolyspora hirsuta (ATCC 27875 $)$; X53197, Saccharopolyspora hordei (A54 ${ }^{\mathrm{T}}$ ); X53194, Saccharopolyspora rectivirgula (ATCC 33515); X76967, Saccharopolyspora sp. (A215); X53193, Saccharothrix australiensis (ATCC $31947^{\mathrm{T}}$ ); X76963, Saccharothrix coeruleofusca (DSM $\left.43679^{\mathrm{T}}\right)$; X76964, Saccharothrix longispora (DSM 43749 ${ }^{\mathrm{T}}$ ); X76965, Saccharothrix mutabilis subsp. capreolus (DSM 40225 ); X76966, Saccharothrix mutabilis subsp. mutabilis $\left(\right.$ DSM $\left.43853^{\mathrm{T}}\right) ; \mathrm{X} 53163$, Streptomyces albus (DSM $\left.40313^{\mathrm{T}}\right)$; X53162, Streptomyces brasiliensis (DSM 43159 ); X53161, Streptomyces diastaticus (DSM 40496 ${ }^{\mathrm{T}}$ ); X53173, Streptomyces lavendulae (DSM 2014 $) ; \mathrm{Y} 00484$, Streptomyces lividans (TK21); X53170, Streptomyces purpureus (DSM $43460^{\mathrm{T}}$ ); X81574, Streptomyces sp. (NRRL 3890); X53168, Streptoverticillium abikoense (DSM 40831 $)$; X53164, Streptoverticillium baldacii (DPDU 0819 ${ }^{\mathrm{T}}$ ); X53165, Streptoverticillium cinnamoneum subsp. azacolatum (DPDU 0074 $)$; X53171, Streptoverticillium cinnamoneum subsp. cinnamoneum (DPDU 0093 ${ }^{\mathrm{T}}$ ); X53167, Streptoverticillium ladakanum var. ladakanum (DSM 40587 ${ }^{\mathrm{T}}$ ); X53172, Streptoverticillium luteoreticuli (DPDU 0081); X79323, Streptoverticillium mashuense (DSM 40221); X53166, Streptoverticillium olivoreticuli subsp. cellulophilum (DPDU 0278 ); and X53169, Streptoverticillium salmonis (DPDU 0098). The genus specificity of oligonucleotides was tested against all DNA sequences available in the EMBL database with the FASTA program. The melting temperature $\left(T_{\mathrm{m}}\right)$ was estimated according to Thomas \& Dancis (1973) and the Lathe's (1985) formula (Stahl \& Amann, 1991). Relative $T_{\mathrm{m}}$ values obtained using $0.3 \mathrm{M}$ as a standard salt concentration were used to design pairs of primers with similarly high $T_{\mathrm{m}}$. The probabilities of primer-dimer formation and autofolding were also studied to keep them as low as possible. 
The designed oligonucleotides, supplied by Pharmacia Biotech, are as follows $(\mathrm{M}=\mathrm{C}$ or $\mathrm{A})$ : $\mathrm{SP1}, 5^{\prime}$ GTGGAACCCATCCCCACACC 3'; SP2, 5' GTGGAAMCAGTCCCCACACC 3'; SP3, 5' GGTGACGGTAGGTGTAGAAG $3^{\prime}$; AMP3， 5' GCGGCACAGAGACCGTGGAAT 3'; AMP2, 5' GTGGAAAGTTTTTTCGGCTGGGG 3'; AMP4, 5' GCGGCACAGAAACCGTGGAAT $3^{\prime}$; and AMP5, 5' GTGGAAAGTTTTTTCGGTGGGGG 3'.

DNA extraction. Total genomic DNAs from the different micro-organisms used in this study were recovered and purified as described previously (Innis et al., 1990).

PCR amplification. DNA preparations were used as template DNA for $T a q$ polymerase. Reactions were performed in a final volume of $25 \mu \mathrm{l}$ containing $0.2 \mathrm{mM}$ each of the four dNTPs (Roche), $0 \cdot 1 \mu \mathrm{M}$ each primer, $5 \mu$ l extracted DNA (1/100 dilution) and $0.5 \mathrm{U}$ Taq polymerase (Appligene) with its appropriate reaction buffer. Controls without bacterial DNA were included for each PCR experiment. Amplifications were performed in a Perkin Elmer Cetus DNA Thermal Cycler 480, according to the following profile: 40 cycles of $30 \mathrm{~s}$ at $93^{\circ} \mathrm{C}, 30 \mathrm{~s}$ at $53^{\circ} \mathrm{C}$ and $2 \mathrm{~min}$ at $72^{\circ} \mathrm{C}$; followed by $10 \mathrm{~min}$ at $72^{\circ} \mathrm{C}$. In the case of amplification with AMP4/AMP5, the annealing temperature was $60^{\circ} \mathrm{C}$ instead of $53{ }^{\circ} \mathrm{C}$. Amplification products were analysed by electrophoresis $\left(0.25 \mathrm{~V} \mathrm{~cm}^{-2}\right)$ in $1.2 \%(\mathrm{w} / \mathrm{v})$ agarose gels stained with ethidium bromide.

Direct sequencing of PCR products. The $16 \mathrm{~S}$ rDNA sequences corresponding to the oligonucleotides SP1/SP2 (nucleotides 801-819) and to SP3 (nucleotides 450-469) were determined as follows for a group of strains of Saccharopolyspora (reference and wild-type strains). The sequence between nucleotides 801-809 was determined using two oligonucleotides, SQ1 (5' GCGAACAGGATTAGATACCCTGG $\left.3^{\prime}\right)$ and SQ2 (5' CATCTCACGACACGAGCTGACG $3^{\prime}$ ), which were designed to match the conserved sequences flanking this region. The sequences of these primers correspond to nucleotide positions $750-772$ and 1035-1056, respectively. The amplification products obtained with SP3/SQ2 were sequenced directly with the T7 Sequenase v2.0 PCR product sequencing kit (Amersham). The sequence was determined in both strands using SQ1 and SQ2, respectively. Alternatively, a third primer, 685d3 (5' GTAGCGGTGAAATGCGCAGA 3'; Lane, 1991), corresponding to nucleotides 657-676, was also used to sequence one of the strands. The sequence between nucleotides $450-469$ was determined using two oligonucleotides, F243 (Heuer et al., 1997 ) and $685 \mathrm{r} 3$ (Lane, 1991), that match conserved sequences flanking this region. The sequences of these primers correspond to nucleotide positions $218-235$ and $657-676$, respectively. The amplification products obtained with F243/SP1 were sequenced in both strands using F243 and 685r3 (Heuer et al., 1997).

In the case of Pseudonocardia strains, the 16S rDNA sequences corresponding to oligonucleotides AMP2 (nucleotides 197-219) and AMP3 (nucleotides 813-833) were determined for a series of wild-type strains as indicated below. The amplification products containing the sequence of AMP2 between nucleotides 197-219 were obtained with the oligonucleotides 27F (Lane, 1991) and AMP3. Both strands were sequenced using the oligonucleotides $27 \mathrm{~F}$ and $342 \mathrm{r}$ as sequencing primers (Lane, 1991). The sequence of AMP3 between nucleotides 813-833 was determined in both strands from an amplification product obtained with the primers AMP2 and SQ2; oligonucleotides 685d3 (complementary to $685 \mathrm{r} 3$ ) and $\mathrm{SQ} 2$ were used as sequencing primers.
Whole-cell fatty acid composition. Cultures were grown as confluent patches on YCZ $[0.05 \%$ yeast extract and $1.17 \%$ (w/v) Czapek Dox (Difco)] agar at $28^{\circ} \mathrm{C}$ for $10 \mathrm{~d}$. Vegetative growth was then scraped $(100-200 \mathrm{mg})$ and fatty acid methyl esters (FAMEs) were prepared using a modified sample preparation (Sasser, 1990). FAME analysis was carried out by capillary GC using a Hewlett-Packard model 5890 GC/MIDI system (Microbial ID) equipped with a phenylmethylsilicone column $(0.2 \mathrm{~mm} \times 25 \mathrm{~m})$. Chromatography conditions were as recommended by the manufacturer. Individual FAME identification and clustering analysis were performed using the MIS software (Microbial ID).

\section{RESULTS AND DISCUSSION}

In this work, the design of two sets of genus-specific pairs of primers for the selective amplification of the 16S rDNA region of the genera Pseudonocardia and Saccharopolyspora is described. The search for conserved sequences within a given genus was based on comparative analysis of variable regions of the known $16 \mathrm{~S}$ rRNA sequences. The strains listed in the Methods include representatives from different members of the family Pseudonocardiaceae as well as the related genera Saccharothrix and Actinokineospora. Sequences from 16 Streptomyces strains were also included in this analysis to rule out any homology of sequences of strains of Pseudonocardia and Saccharopolyspora with representatives of the genus Streptomyces.

The analysis was performed by alignment of all the sequences using the PILEUP function of the GCG software. A detailed study of the aligned sequences allowed the localization of six variable regions in the $16 \mathrm{~S}$ rDNA sequence corresponding to nucleotide positions $170-230,430-580,560-640,790-830,960$ 1020 and $1090-1130$ of the Streptomyces ambofaciens 16S rDNA gene (Pernodet et al., 1989). Three of these sequences (positions 170-230, 960-1020 and 1090 1120 , respectively) corresponded to the alpha, beta and gamma regions previously described for the genus Streptomyces (Stackebrandt et al., 1992). The search for genus-specific sequences was focussed on these six variable regions and, from the beginning, the region between nucleotides 790-830 appeared to be the most promising, given the high sequence conservation found within each genus. This homology remained high enough to consider the design of genus-specific primers. Two additional regions, corresponding to positions 197-230 and 430-580, also showed an appropriate degree of conservation within certain genera and were also suitable for this purpose. However, analysis of sequences in the other hypervariable regions showed such a low homology within each genus that these sequences may only be used at the species or even strain level.

\section{Specific primers for the genus Pseudonocardia}

When the 16S rRNA region between nucleotides 813-833 from different representatives of the genus Pseudonocardia was examined in detail, it was observed that the sequence in this region seemed to be unique for 
(a)

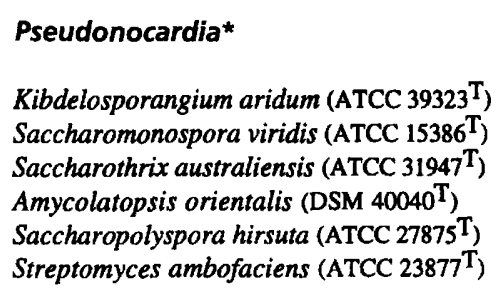

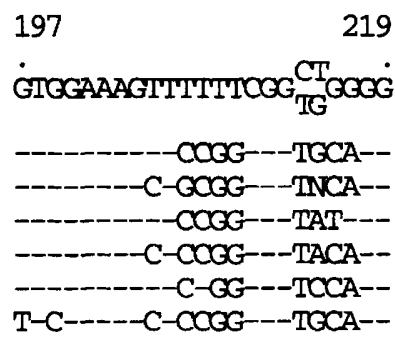

AMP2 $\rightarrow$ 5' GIGGAAAGTTTITICGG ${ }_{\text {TG }}^{\text {GT }}$ GGG 3' AMP5 $\rightarrow$

(b)

\section{Saccharopolyspora† \\ Kibdelosporangium aridum (ATCC $39323^{\mathrm{T}}$ ) Saccharomonospora viridis (ATCC 15386 ${ }^{\mathrm{T}}$ ) Saccharothrix australiensis (ATCC $31947^{\mathrm{T}}$ ) Amycolatopsis orientalis (DSM 40040 $\mathrm{T}$ ) Pseudonocardia thermophila (ATCC 19285 ${ }^{\mathrm{T}}$ ) Streptomyces ambofaciens (ATCC $23877 \mathrm{~T}$ )}

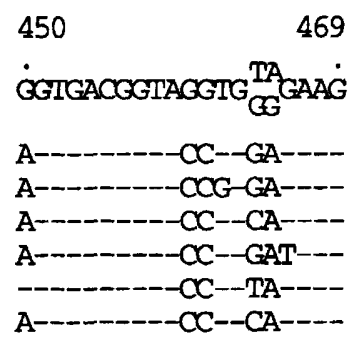

SP3 $\rightarrow$

5' GGIGACGGTAGGTGTAGAAG 3'
813

833
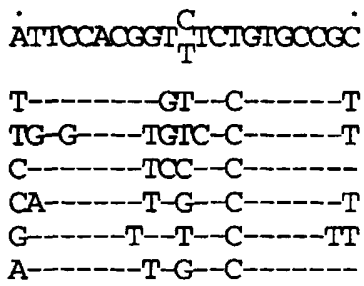

$\leftarrow$ AMP3

3'TAAGGTGCCA G'AGACACGGCG 5'

$\leftarrow$ AMP4

801

819

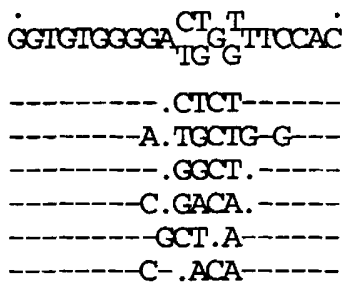

$\leftarrow$ SP2

3' $\triangle$ CACACCCCT $\mathrm{AC}$ MAAGIG 5'

$$
\leftarrow \text { SP1 }
$$

Fig. 1. Comparison of the 16S rRNA-DNA sequences of representatives of different genera of the family Pseudonocardiaceae and Streptomyces ambofaciens in the regions where the specific oligonucleotides are located. (a) Sequence of the nucleotide regions 197-219 and 813-833; *, consensus sequences for the genus Pseudonocardia from which the oligonucleotides AMP2/AMP5 and AMP3/AMP4 were designed, respectively ( $N$ = any nucleotide). (b) Sequence of the regions $450-469$ and $801-820 ; t$, consensus sequences for the genus Saccharopolyspora from which SP3 and SP2/SP1 were designed (degenerate position $\mathrm{M}=\mathrm{C}$ or $\mathrm{A}$ ).

this genus (Fig. 1a). However, based on a single base change in this region (nucleotide position 823 ), strains were divided into two different groups: one formed by the strains Pseudonocardia alni, Pseudonocardia hydrocarbonoxydans, Pseudonocardia petroleophila, Pseudonocardia saturnea, Pseudonocardia halophobica, Pseudonocardia compacta and Pseudonocardia thermophila; and a smaller group comprising Pseudonocardia autotrophica and 'Pseudonocardia nitrificans'. Although the sequences of both groups of strains differed by just one nucleotide in this region, analysis of the whole 16S rRNA showed how the sequences of these strains usually divide into the same two groups in the variable regions of these molecules, which could indicate a phylogenetic clustering within the genus. In order to assess this possibility, two different reverse primers were designed that differ in this single nucleotide: AMP3 (5' GCGGCACAGAGACCGTGGAAT $\left.3^{\prime}\right)$, which is specific for the largest group of sequences; and AMP4 (5' GCGGCACAGAAACCGTGGAAT
3'), which matches the strains of Pseudonocardia autotrophica and 'Pseudonocardia nitrificans' (Fig. 1a).

Another conserved region observed in the members of this genus was also found around nucleotide positions 197-219 and this sequence was selected for the design of the forward primer (Fig. 1a). Again, two differences in the sequences in this region (nucleotide positions 214 and 215) divided the species of this genus into the same two groups mentioned above. Therefore, two forward primers were constructed: AMP2 (5' GTGGAAAGTTTTTTCGGCTGGGG 3'), which is specific for the same group of sequences as AMP3; and AMP5 (5' GTGGAAAGTTTTTTCGGTGGGGG 3'), to be used in the amplification assays in combination with AMP4. According to the sequence, the expected size of the amplification product using both pairs of oligonucleotides, AMP3/AMP2 or AMP4/AMP5, is $640 \mathrm{bp}$ (Fig. 1a).

To test the genus specificity of these two pairs of 

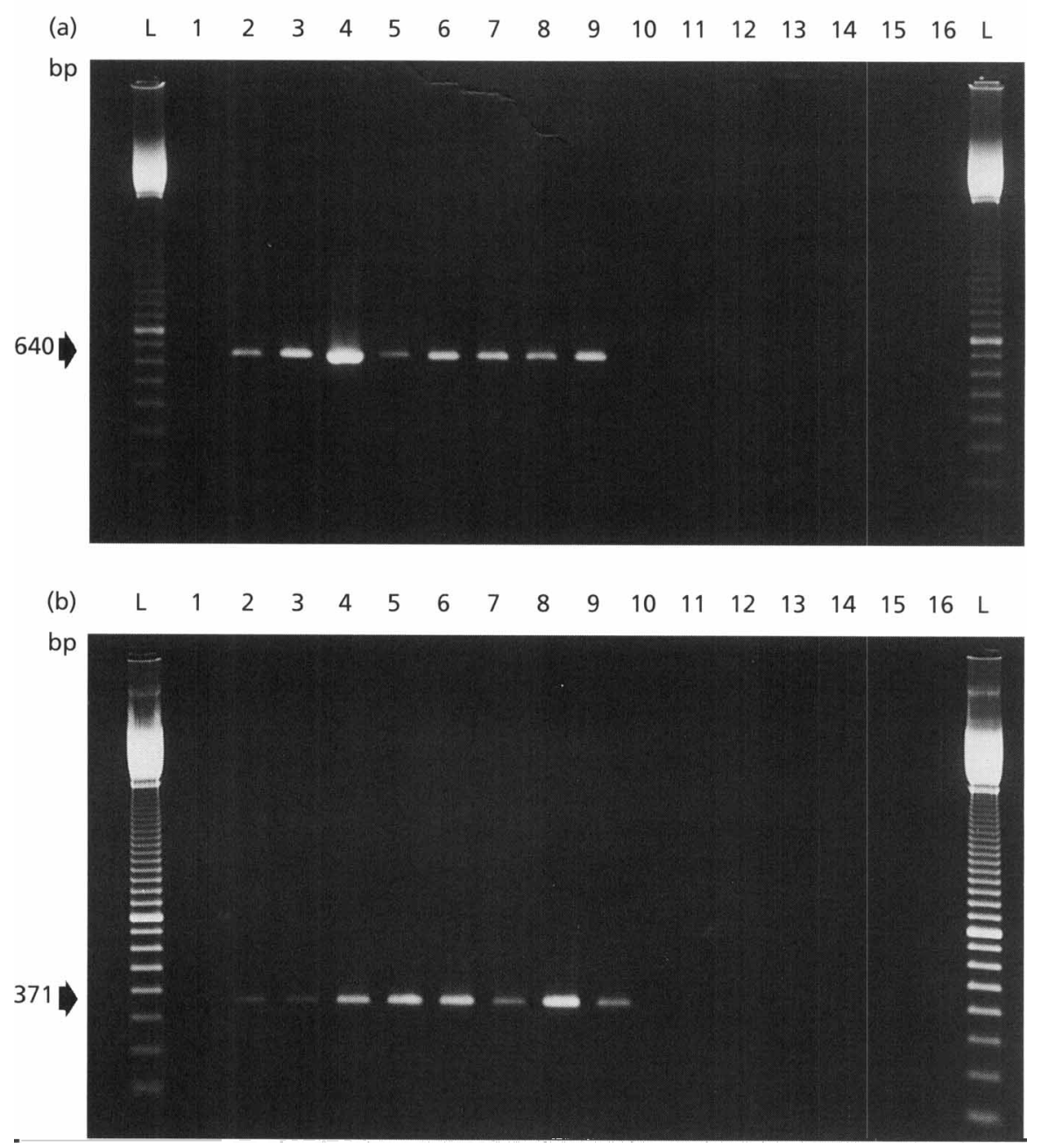

Fig. 2. Agarose gel electrophoresis of $P C R$ products. (a) Selective amplification of the 640 bp fragment using primers AMP2/AMP3 specific for the genus Pseudonocardia. Lanes: 1, control reaction without DNA; 2, Pseudonocardia autotrophica; 3, Pseudonocardia compacta; 4, Pseudonocardia halophobica; 5, Pseudonocardia hydrocarbonoxydans; 6 , 'Pseudonocardia nitrificans'; 7, Pseudonocardia petroleophila; 8, Pseudonocardia saturnea; 9, Pseudonocardia thermophila; 10, Saccharopolyspora hirsuta subsp. hirsuta; 11, Amycolatopsis orientalis subsp. orientalis; 12, Saccharomonospora viridis; 13, Kibdelosporangium aridum; 14, Saccharothrix aerocolonigenes; 15, Actinomadura pusilla; and 16, Streptomyces cattleya. (b) Selective amplification of the $371 \mathrm{bp}$ fragment using primers SP1/SP3 specific for the genus Saccharopolyspora. Lanes: 1, control reaction without DNA; 2, Saccharopolyspora erythraea; 3, Saccharopolyspora gregorii; 4, Saccharopolyspora hirsuta subsp. hirsuta; 5, Saccharopolyspora hirsuta subsp. kobensis; 6, Saccharopolyspora hordei; 7, Saccharopolyspora rectivirgula; 8, Saccharopolyspora spinosa; 9, Saccharopolyspora taberi; 10, Pseudonocardia compacta; 11, Amycolatopsis orientalis subsp. orientalis; 12, Saccharomonospora viridis; 13, Kibdelosporangium aridum; 14, Actinomadura pusilla; and 15, Streptomyces cattleya. In (a) and (b) lane L, molecular mass marker (100 bp ladder; Pharmacia Biotech).

oligonucleotides, PCR assays were performed using template DNAs isolated from a series of reference strains of 11 different genera (Table 1). Using the AMP3/AMP2 primer pair and an annealing temperature of $53^{\circ} \mathrm{C}$, the specific amplification product of $640 \mathrm{bp}$ was obtained from all strains of the eight different species of Pseudonocardia tested [Pseudonocardia autotrophica (three strains), Pseudonocardia compacta, Pseudonocardia halophobica, Pseudonocardia hydrocarbonoxydans, 'Pseudonocardia nitrificans', Pseudonocardia petroleophila, Pseudonocardia saturnea and Pseudonocardia thermophila]. It should be noted that this pair of primers is specific for all strains of Pseudonocardia tested, in spite of their sequence differences. No amplification products were detected in control experiments performed with DNAs from any of the other bacterial strains analysed (Table 1; Fig. 2a). To confirm that this lack of amplification with the reference strains other than Pseudonocardia was not due to the potentially poor condition of the DNA extracts, amplification reactions were performed with previously published primers, designed specifically for actinomycetes (F243) and for Gram-positive bacteria (R513), under the conditions recommended 
by Heuer et al. (1997). The expected amplification product of $271 \mathrm{bp}$ was observed in all actinomycete strains tested.

When the specificity of the AMP4/AMP5 primer pair was tested under the same reaction conditions with this group of strains, the annealing temperature of $53{ }^{\circ} \mathrm{C}$ proved to be too low and non-specific bands were observed in the DNA amplification products from several strains belonging to other genera. Experiments were performed at different annealing temperatures and it was found that increasing this temperature to $60{ }^{\circ} \mathrm{C}$ rendered the pair of primers specific for the genus Pseudonocardia. At $60{ }^{\circ} \mathrm{C}$, a single PCR amplification product of $640 \mathrm{bp}$ was obtained from all strains of Pseudonocardia tested. Again, no amplification products were detected when template DNAs from all the other reference strains were used. The specificity of the AMP2/AMP3 pair was also confirmed at $60{ }^{\circ} \mathrm{C}$ with all the reference strains of Pseudonocardia tested.

These results show that both pairs of primers, AMP3/ AMP2 and AMP4/AMP5, allow identification of all the tested strains belonging to the genus, in spite of the differences observed in their sequences. The lowstringency conditions used in the PCR reaction were not selective enough to distinguish between sequences which differ in just one nucleotide. On the other hand, the AMP2/AMP3 pair is genus-specific at a lower annealing temperature $\left(53^{\circ} \mathrm{C}\right)$, providing a much more accurate tool for the detection and identification of members of this genus. In fact, comparative analysis of AMP3 and AMP4, in which both sequences correspond to the nucleotide region 813-833, with sequences from other representative type species showed that the single base change makes AMP3 more genusspecific than AMP4. In the case of the oligonucleotides AMP2 and AMP5, there is a difference at two positions. These nucleotides in AMP2 (CT) do not occur in any of the tested reference strains, whereas the corresponding nucleotides in AMP5 (TG) are also shared by other genera and make this primer less specific (Fig. 1a). In consequence, the AMP2/AMP3 pair was finally selected to be used in the subsequent amplification experiments.

To rule out possible PCR amplification with primers AMP2/AMP3 of 16S rDNA sequences other than those of the genera already tested, FASTA analysis was carried out against all the DNA sequences available in GenBank. It was found that, although oligonucleotide AMP2 showed total homology with sequences of two unidentified isolates (U27857 and D50066) and a strain of Microsphaera multipartita (Y08541), no homology was observed with any of these sequences with AMP3, and therefore no amplification could be expected in these cases. High homology of AMP2 was also obtained with a series of sequences of different species of the genera Microbispora (U48984 and D86936), Microtetraspora (D85490 and U48976), Planobispora (D85494), Planotetraspora (D85496) and Strepto- sporangium (X89934, X89937, X89939, X89943, X89944, U48976, X89953, X89955 and X89958) among others. All these sequences showed a single nucleotide difference at position 214. Although effective binding of AMP2 to these sequences could be expected, these strains showed at least three, as in the case of Microbispora rosea (D86936), or four different bases in their sequence corresponding to the other primer AMP3; therefore, amplification should not be expected using this pair of primers. To experimentally verify this hypothesis, the DNA of representative reference strains [Microbispora aerata ATCC $1544^{\mathrm{T}}$ (U48984), Microbispora rosea ATCC 12950 (D86936), Microtetraspora glauca ATCC $23057^{\mathrm{T}}$ (D85490), Microtetraspora niveoalba ATCC $27301^{\mathrm{T}}$ (U48976), Streptosporangium roseum ATCC $12428^{\mathrm{T}}$ (U48976) and Streptosporangium vulgare ATCC $33329^{\mathrm{T}}$ (X89955)] was tested with the AMP2/AMP3 pair. No amplification was obtained at $53{ }^{\circ} \mathrm{C}$ with any of these strains except for Microbispora rosea ATCC $12950^{\mathrm{T}}$, which positively amplified with these primers. When the DNA from this strain was tested at an annealing temperature of $60^{\circ} \mathrm{C}$, no amplification product was obtained, confirming the specificity of these primers for sequences of the genus Pseudonocardia at this temperature.

The only complete homology found for the primer AMP3 corresponded to the sequence of Actinobispora yunnanensis IFO15681 (D85472), a member of the Pseudonocardiaceae. The primer AMP2 did not perfectly match the corresponding sequence of this strain which presented one deletion in one of the series of six $\mathrm{T}$ bases in the sequence.

\section{Genus-specific primers for Saccharopolyspora}

The same strategy was used in the design of oligonucleotides specific for the identification of members of the genus Saccharopolyspora. After a close examination of the conservation of the 16S rDNA region around nucleotides 801-819 of the sequenced strains of Saccharopolyspora, two groups of sequences could be defined (Fig. 1b). One group included strains of Saccharopolyspora hirsuta subsp. hirsuta, Saccharopolyspora hordei and Saccharopolyspora sp. (A215), whereas the second group comprised strains of Saccharopolyspora erythraea, Saccharopolyspora gregorii and Saccharopolyspora rectivirgula (Table 1). According to the differences in their sequence, two reverse oligonucleotides, SP1 (5' GTGGAACCCATCCCCACACC $\left.3^{\prime}\right)$ and SP2 (5' GTGGAAMCAGTCCCCACACC $3^{\prime}$ ), were constructed that were directed to each of the groups mentioned above. The lack of complete conservation within the second group of sequences required the use of a degenerate nucleotide within SP2 (Fig. 1b).

To define a specific oligonucleotide to be used as a forward PCR primer, the remaining upstream variable sequences were studied and the region included within positions $450-469$ was selected. In this case, identical 
sequences were found for different strains of Saccharopolyspora (Saccharopolyspora hirsuta subsp. hirsuta, Saccharopolyspora hordei, Saccharopolyspora erythraea and Saccharopolyspora gregorii). The exception was a strain of Saccharopolyspora rectivirgula ATCC 33515 , which differed at only two positions (nucleotides 464 and 465) and the Saccharopolyspora sp. A215 strain which differed at positions 460 and 461 . This region was used to design the forward oligonucleotide SP3 (5' GGTGACGGTAGGTGTAGAAG $\left.3^{\prime}\right)$. The expected size of the PCR product using either SP1/SP3 or SP2/SP3 as amplification primers, was $371 \mathrm{bp}$ (Fig. $1 b)$.

To examine the genus specificity of both primer combinations, they were tested in PCR reactions at an annealing temperature of $53^{\circ} \mathrm{C}$ with chromosomal DNAs extracted from all the bacterial strains listed in Table 1. In spite of the sequence differences between SP1 and SP2, both primers were able to hybridize to all the Saccharopolyspora sequences. No amplification products were observed with the other reference strains, whereas in all these strains, a PCR fragment was obtained with the pair of primers F243/R513 for actinomycetes.

The same amplification product of $371 \mathrm{bp}$ was obtained with both pairs of primers, SP1/SP3 and SP2/SP3, from all the Saccharopolyspora strains tested [Saccharopolyspora erythraea, Saccharopolyspora gregorii, Saccharopolyspora hirsuta subsp. hirsuta (two strains), Saccharopolyspora hirsuta kobensis, Saccharopolyspora hordei, Saccharopolyspora rectivirgula (two strains), Saccharopolyspora spinosa (two strains) and Saccharopolyspora taberi]. In fact, two strains of Saccharopolyspora rectivirgula which were positively identified with the primers, contained sequences around positions $450-469$ that do not perfectly match with SP3 (nucleotide positions 464 and 465), but still produce the $371 \mathrm{bp}$ amplification fragment. The effect of this divergence was only observed when the annealing temperature was increased by at least $4{ }^{\circ} \mathrm{C}$. In this case, experiments done at annealing temperatures of $57^{\circ} \mathrm{C}$ or higher failed to produce amplification fragments. In the case of the strain of Saccharopolyspora A215, positive amplification with the primers SP1/SP3 would be expected, taking into account the results obtained with Saccharopolyspora rectivirgula. Nevertheless, these data will need to be confirmed experimentally.

At the time when these experiments were performed, the sequence of this region was not available for two strains of Saccharopolyspora (Saccharopolyspora spinosa and Saccharopolyspora rectivirgula), which also produce the expected amplification fragment. To confirm their sequence homology, either to SP1 or SP2, both strands of the region at positions 801-819 were sequenced from two of these strains. As expected, the sequence from Saccharopolyspora spinosa NRRL 18537 (AF061977) perfectly matched the sequence of primer SP1, whereas that of Saccharopolyspora rectivirgula ATCC 15347 (AF061976) matched SP2.
Under the low-stringency conditions used, both pairs of primers (SP1/SP3 and SP2/SP3) showed the same specificity for all the strains of Saccharopolyspora tested, including those whose sequences did not match perfectly. As mentioned above, the sequence specificity of the oligonucleotides showed only when the annealing temperature in the PCR reaction was above $57^{\circ} \mathrm{C}$. In fact, at annealing temperatures of $57^{\circ} \mathrm{C}$ Saccharopolyspora rectivirgula did not always present an amplification product and when the annealing temperature was increased to $60{ }^{\circ} \mathrm{C}$, PCR reactions with SP1/SP3 did not produce a band with strains from the group which matches with SP2 and vice versa.

\section{Identification of wild-type isolates}

Once the genus specificity of the oligonucleotides had been verified on the reference strains from culture collections, the probes were tested as identification tools for potential members of the genera Pseudonocardia and Saccharopolyspora. A group of 106 wildtype actinomycetes, obtained in the course of a screening programme from a large diversity of geographic origins (Table 2), was tested. These strains had been tentatively assigned to the family Pseudonocardiaceae on the basis of their microscopic morphological characters. According to the results presented above, the AMP3/AMP2 primer pair, which allows genus-specific amplification under low-stringency conditions, was selected to identify those members of the genus Pseudonocardia. In the case of the genus Saccharopolyspora, the SP1/SP3 primer pair was used. Under the conditions used in the PCR assay, the same information could be obtained with the other two pairs of oligonucleotides, AMP4/AMP5 and SP2/SP3, respectively. DNA was extracted from each of the 106 wild-type strains and was amplified in two parallel PCR assays with AMP3/AMP2 and SP1/SP3. Of the 106 isolates, 51 produced a $640 \mathrm{bp}$ amplification product with AMP3/AMP2, whereas no PCR products were obtained with SP1/SP3. According to these results, the 51 strains were tentatively assigned to the genus Pseudonocardia. On the other hand, only nine wild-type strains gave an amplification product of 371 bp with SP1/SP3 and no amplification was observed with the oligonucleotides specific for Pseudonocardia. These cultures were thus identified as strains of the genus Saccharopolyspora. The remaining isolates gave no amplification products with either pair of oligonucleotides. Again, the quality of these DNA extracts was tested with primers F243/R513 and, in all cases, an amplification product of the expected size for actinomycetes was observed. These strains probably correspond to members of the other related genera of the family.

\section{Diversity of the strains identified with the probes}

To determine the diversity of the isolates that could be detected within a genus with these oligonucleotides, the existing relationship of the isolates to the reference strains used in this study was examined by FAME 
Euclidian distance

40
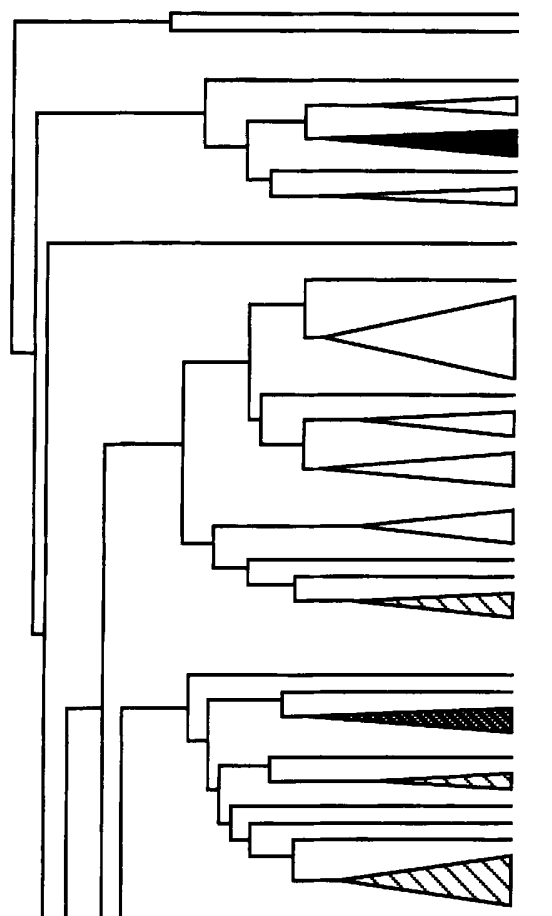

Pseudonocardia sp. 01

Pseudonocardia petroleophila

wt E12

wt $\mathrm{C} 12$ and wt $\mathrm{A} 8$

Amycolatopsis orientalis subsp. orientalis (a),

Pseudonocardia sp. A9, wt A10

wt G9

wt $\mathrm{C} 1$ and wt $\mathrm{C} 3$

Pseudonocardia sp. A5

Amycolatopsis sulphurea

[Amycolatopsis orientalis(b, c, d), Amycolatopsis azurea

Amycolatopsis sp. C2, E15, G1, B8 and H4, wt G16

Saccharothrix flava

Amycolatopsis sp. E3, G18 and G21

[Amycolatopsis orientalis subsp. orientalis $(\mathrm{e})$

Amycolatopsis sp. $\mathrm{C} 18$ and $\mathrm{H} 16$, wt G2

Saccharothrix mutabilis subsp. mutabilis, Amycolatopsis

orientalis subsp. orientalis ( $\mathrm{f}$ ), wt E14 and wt G3

wt strain

Saccharopolyspora hirsuta subsp. hirsuta (g)

Saccharothrix syringae.

Saccharothrix mutabilis subsp. capreolus,

Saccharopolyspora hirsuta subsp. kobensis

Pseudonocardia sp. E8

Saccharopolyspora sp. A15

Pseudonocardia thermophila, Saccharopolyspora hordei.

Pseudonocardia thermophila

Saccharopolyspora sp. $\mathrm{s}^{\mathrm{H}} 3$
Pseudonocardia $\mathrm{sp} . \mathrm{G}$

Saccharopolyspora erythraea, Saccharopolyspora sp. E20

Sacccharopolyspora sp. C21

Saccharopolyspora spinosa

Saccharopolyspora hirsuta subsp. hirsuta (h),

Saccharopolyspora gregorii,
Saccharopolyspora sp. E10, H11, H18 and H13

"Pseudonocardia nitrificans", Pseudonocardia sp. D17 Pseudonocardia sp. E16

Pseudonocardia sp. B5, G13, E13, B11, C10, G23 and D11

[Pseudonocardia autotrophica $(\mathrm{i}, \mathrm{j})$, Pseudonocardia saturnea,

Pseudonocardia sp. B4 and $\mathrm{H} 8$

Saccharomonospora azurea

Saccharomonospora az
Pseudonocardia sp. G6

[ Pseudonocardia sp. E11, C7, G14, B1, D12, B3, H10, D15,

A6, B7 and C6

Pseudonocardia sp. C5, C17, H9 and B9

[Pseudonocardia sp. A1, H17, A3, D14, E9, D16, D2, D7, D1 and D8

Pseudonocardia halophobica

[ Saccharomonospora cyanea, Saccharomonospora viridis

[ Saccharomonospora cyanea, S

Amycolatopsis fastidiosa, wt $\mathrm{C} 11$ and wt B12

wt D18

Amycolatopsis methanolica, Actinopolyspora thermovinacea,

wt D3

Pseudonocardia compacta

Pseudonocardia hydrocarbonoxydans

Pseudonocardia sp. A12

Saccharothrix aerocolonigenes $(\mathbf{k}, 1)$,

Saccharothrix waywayandensis, wt $\mathrm{H} 5$ and wt $\mathrm{H} 6$

Pseudonocardia sp. E7

Pseudonocardia sp. E19 and A4
Fig. 3. Dendrogram showing the diversity of the wild-type (wt) strains identified with probes specific for the genera Pseudonocardia and Saccharopolyspora and their relationship to the reference strains of the family Pseudonocardiaceae. Reference strains are those included in Table 1 Cultures marked (a) to (I) correspond to strains of the same species: (a), Amycolatopsis orientalis subsp. orientalis ATCC 21425; (b, c, d), Amycolatopsis orientalis NRRL 18098, NRRL 18099 and NRRL 18100, respectively; (e), Amycolatopsis orientalis subsp. orientalis DSM 40040; (f), Amycolatopsis orientalis subsp. orientalis NRRL 2452; (g), Saccharopolyspora hirsuta subsp. hirsuta NRRL B5792': (h), Saccharopolyspora hirsuta subsp. hirsuta ATCC 27876; (i, j), Pseudonocardia autotrophica ATCC $19727^{\top}$ and DSM 43098, respectively; ( $k$, I), Saccharothrix aerocolonigenes ATCC 39243 and NRRL B3298 ${ }^{\top}$, respectively. Strains referred to as Amycolatopsis sp. correspond to wild-type strains identified as members of the genus Amycolatopsis by means of a pair of PCR primers designed specifically for several species of this genus (unpublished data). composition analysis (Embley et al., 1987; Embley \& Wait, 1994). The fatty acid composition of a group of 121 strains was analysed, including 39 reference strains of the genera Amycolatopsis (ten strains), Saccharopolyspora (eight strains), Saccharomonospora (four strains), Pseudonocardia (nine strains) and Saccharothrix (seven strains) (Table 1), and a subset of 82 wildtype isolates selected from the group of 106 actino- mycetes previously mentioned, which contained strains that were positively identified to the genus level by PCR. Cluster analysis of the strains was based on their fatty acid profiles and their relationship was established in a dendrogram generated by treating the Euclidian distances of the fatty acids with the unweighted pair group method with arithmetic mean algorithm (Fig. 3). 
Table 3. Partial 16S rDNA sequences of the wild-type isolates assigned to the genus Saccharopolyspora

\begin{tabular}{|c|c|c|c|c|c|}
\hline \multirow[t]{2}{*}{ Strain } & & \multicolumn{2}{|c|}{ Nucleotide sequence region } & \multirow{2}{*}{\multicolumn{2}{|c|}{ GenBank no. }} \\
\hline & & $450-469$ & 801-819 & & \\
\hline & SP3 & GGTGACGGTAGGTGTAGAAG & $\begin{array}{l}\text { GGTGTGGGGATGGGTTCCAC } \\
\text { GGTGTGGGGACTGTTTCCAC }\end{array}$ & $\begin{array}{l}\mathrm{SP} 1^{*} \\
\mathrm{SP} 2^{*}\end{array}$ & \\
\hline CIBE A15 & & GGTGACGGTAGGTGTAGAAG & GGTGTGGGGATGGGTTCCAC & & AF064978 \\
\hline CIBE C21 & & GGTGACGGTAGGTGTAGAAG & GGTGTGGGGATGGGTTCCAC & & AF064979 \\
\hline CIBE E10 & & GGTGACGGTAGGTGTAGAAG & GGTGTGGGGATGGGTTCCAC & & AF064980 \\
\hline CIBE H3 & & GTTGACGGTAGGTGTAGAAG & GGTGTGNGGATGGGTTCCNN & & AF064981 \\
\hline CIBE E20 & & GGTGACGGTAGGTGTAGAAG & GGTGTGGGGACTGTTTCCAC & & AF064982, AF064983 \\
\hline
\end{tabular}

* For the best comparison with the sequenced regions, complementary sequences are shown for reverse primers SP1 and SP2.

Strains of the genus Saccharopolyspora clustered in a homogeneous group defined at a Euclidian distance below $21 \cdot 0$. Within this cluster, six of the eight reference Saccharopolyspora strains used in this study (Saccharopolyspora erythraea, Saccharopolyspora gregorii, Saccharopolyspora hirsuta subsp. hirsuta, Saccharopolyspora hordei, Saccharopolyspora spinosa and Saccharopolyspora taberi) and eight wild-type strains that had been positively assigned to this genus by PCR were included. The only exceptions were two strains of Saccharopolyspora hirsuta (Saccharopolyspora hirsuta subsp. hirsuta and Saccharopolyspora hirsuta subsp. kobensis) that were found in a separate branch of the dendrogram (Fig. 3). It is interesting to note that the phenotypic homogeneity observed for the group of wild-type strains of Saccharopolyspora contrasts with the diversity in the geographic source of the isolates (Table 2).

In contrast to the genus Saccharopolyspora, strains of Pseudonocardia tested (reference strains and wild-type isolates) that produced a specific PCR amplification product with the oligonucleotides designed for this genus were distributed in 13 different branches of the dendrogram defined at a Euclidian distance below $21 \cdot 0$. The largest group of wild-type strains assigned by PCR to this genus ( 37 out of 46 isolates) was contained within a single cluster. These strains, although closely related on the basis of their fatty acid profiles, correspond to different isolates and were obtained from quite different environmental substrates and geographic origins (Table 2). This group also included four reference strains of the genus Pseudonocardia ('Pseudonocardia nitrificans' DSM 46012, Pseudonocardia autotrophica ATCC $19727^{\mathrm{T}}$ and DSM 43098, and Pseudonocardia saturnea NRRL B-16172 $)$. The other nine wild-type isolates, as well as five strains of the species Pseudonocardia petroleophila, Pseudonocardia thermophila, Pseudonocardia halophobica, Pseudonocardia compacta and Pseudonocardia hydrocarbonoxydans, used in the study appeared on unique branches of the dendrogram or clustered with other members of the family (Fig. 3).

With regard to the other genera included in the study, the reference strains of the genera Amycolatopsis and Saccharothrix were also distributed in different branches of the dendrogram. One large cluster included six strains of Amycolatopsis (four strains of Amycolatopsis orientalis, Amycolatopsis sulphurea and Amycolatopsis azurea) and five strains of Saccharothrix (three strains of Saccharothrix mutabilis, one of Saccharothrix flava and one of Saccharothrix syringae). Three of the four strains of Saccharomonospora clustered together, whereas the strain of Saccharomonospora azurea was found in another branch related to Pseudonocardia isolates.

Clustering analysis based on fatty acid composition was only used to show the large diversity of new isolates that could be identified to the genus level by means of selective PCR amplification with the specific primers. It was observed that although a large number of wild-type isolates identified with these primers and assigned to the genus Pseudonocardia are associated with the same clusters, many strains also appeared on separate branches of the dendrogram and did not match any of the clusters defined by the fatty acid composition of reference strains. Such a large diversity was not detected with the probes among the strains identified as Saccharopolyspora. In this case, all the strains consistently clustered with the reference strains.

To determine that the strains positively identified with the pairs of primers effectively corresponded to these genera and to discard the possibility of a lack of specificity of the primers as the source of the inconsistencies observed in the clustering, the nucleotide sequences of the $16 \mathrm{~S}$ rDNA regions corresponding to SP1/SP3 and AMP3/AMP2 were determined for a representative subset of wild-type isolates included in the analysis. From the group of wild-type Saccharopolyspora strains, the sequences of five isolates were determined (strains CIBE A15, CIBE C21, CIBE E10, CIBE E20 and CIBE H3) in the regions corresponding to primers SP1/SP3 (Table 3). In all strains except CIBE E20, the sequence between positions 801-819 perfectly matched the sequence of SP1. In strain CIBE E20, the sequence corresponded to that of SP2. Analysis of the sequences between positions $450-469$ 
Table 4. Partial 16S rDNA sequences of the wild-type isolates assigned to the genus Pseudonocardia

Dots indicate the deletion of one of the six $\mathrm{T}$ bases found in wild-type strains.

\begin{tabular}{|c|c|c|c|c|c|}
\hline \multirow[t]{2}{*}{ Strain } & & \multicolumn{2}{|c|}{ Nucleotide sequence region } & \multirow{2}{*}{\multicolumn{2}{|c|}{ GenBank no. }} \\
\hline & & 197-219 & $813-833$ & & \\
\hline & AMP2 & GTGGAAAGTTTTTTCGGCTGGGG & ATTCCACGGTCTCTGTGCCGC & AMP3* & \\
\hline & AMP5 & GTGGAAAGTTTTTTCGGTGGGGG & ATTCCACGGTTTCTGTGCCGC & AMP4* & \\
\hline CIBE G7 & & GTGGAAAG.TTTTTCGGTGGGGG & ATTCCACGGTCTCTGTGCCGC & & AF064968, AF064969 \\
\hline CIBE D11 & & GTGGAAAG.TTTTTCGGCTGGGG & ATTCCACGGTCTCTGTGCCGC & & AF064970 \\
\hline CIBE O1 & & GTGGAAAG.TTTTTCGGTGGGGG & ATTCCACGGTTTCTGTGCCGC & & AF064971, AF064972 \\
\hline CIBE H9 & & GTGGAAAG.TTTTTCGGTGGGGG & ATTCCACGGTCTCTGTGCCGC & & AF064973, AF064975 \\
\hline CIBE A12 & & GTGGAAAGTTTTGTCGGTGGGGG & ATTCCACGGGTTCCGTGCCGC & & AF064976 \\
\hline CIBE A5 & & GTGGAAAG.TTTTTCGGCCTGGG & ATTCCACGGGTTCCGTGCCGC & & AF064977 \\
\hline
\end{tabular}

${ }^{*}$ For the best comparison with the sequenced regions, complementary sequences are shown for reverse primers AMP3 and AMP4.

(primer SP3) showed that all the strains shared the same sequence as SP3 with the exception of CIBE H3, which presented a single base change ( $G$ to $T)$ at position 451. The high degree of conservation of the sequences analysed from the wild-type isolates supports the specificity of the primers used for the identification of the strains.

From the group of Pseudonocardia strains, six isolates were selected (strains CIBE A5, CIBE A12, CIBE D11, CIBE G1, CIBE G7 and CIBE H9) from the group of wild-type strains assigned to this genus from different representative clusters and the nucleotide regions corresponding to the primers AMP3 and AMP2 were sequenced (Table 4). Within the region between positions 197-219, all strains except for CIBE A5 almost exactly matched either the sequence of AMP2 or AMP5, presenting one single difference in their sequences: a deletion of one of the six $T$ bases in the case of strains CIBE G7, D11, O1 and H9, and a base change ( $T$ to $G$ ) at position 208 for strain CIBE A12. In the region between positions 813-833 corresponding to the other pair of primers, the four strains CIBE G7, D11, O1 and H9 showed a perfect match with AMP3 or AMP4. In the case of strain CIBE A12, two substitutions were found at positions 822 and 826 that did not seem to interfere with annealing of the primer. In fact, the DNA from this strain, as well as the DNAs from the other four isolates previously mentioned, positively amplified with the pair of primers even when more restrictive annealing conditions $\left(60^{\circ} \mathrm{C}\right)$ were used. The sequence of strain CIBE A5 was identical to that of strain CIBE A12 in the region 813-833, but in the region 197-219 it showed, in addition to the deletion of one of the six $T$ bases that was already observed in the other strains, three substitutions close to the $3^{\prime}$ end of the primer that should affect primer annealing. Surprisingly, the DNA of this strain positively amplified with AMP2/AMP3 at $60{ }^{\circ} \mathrm{C}$. Further analysis will be necessary to evaluate the degree of variability of these sequences that can be found among wild-type isolates of this taxon. Such analysis may also detect similarities in the sequences with other genera, as observed in the case of the wild-type isolate CIBE D11 and Actinobispora yunnanensis IFO 15681. Both strains share the same sequence in the regions corresponding to both primers AMP2 and AMP3 and therefore positive amplification should also be expected in the case of the Actinobispora strain.

Results obtained here with reference strains as well as the high degree of conservation observed in most of the sequences of the analysed wild-type isolates, validate the specificity of these new primer pairs for $16 \mathrm{~S}$ rDNA sequences of members of the genera Pseudonocardia and Saccharopolyspora. These data support the usefulness of these primers for the tentative assignment of new isolates to this genera from the large numbers of strains which are normally obtained from the environment. In fact, amplification with these primers does not even require the isolation of chromosomal DNA. The same results can be obtained by scraping some mycelium, even from the original colony, and using whole cells directly in the PCR reaction (data not shown). Nevertheless, these tools have their limitations, as some of the exceptions mentioned above have shown, given that they are based on the current available sequence data which are constantly being renewed. Additional applications of these probes, directed to the future in situ identification of the presence of members of these genera in the environment, are being tested, although such kinds of approach would require further optimization of the probes.

\section{REFERENCES}

Embley, T. M. (1992). The family Pseudonocardiaceae. In The Prokaryotes, 2nd edn, pp. 996-1027. Edited by A. Balows, H. G. Trüper, M. Dworkin, W. Harder \& K.-H. Schleifer. New York: Springer.

Embley, T. M. \& Stackebrandt, E. (1994). The molecular phylogeny and systematics of the actinomycetes. Annu Rev Microbiol 48, 257-289. 
Embley, T. M. \& Wait, R. (1994). Structural lipids of eubacteria. Analysis of fatty acid methyl esters by capillary gas chromatography. In Chemical Methods in Prokaryotic Systematics, pp. 131. Edited by M. Goodfellow \& A. G. O'Donnell. Chichester: Wiley.

Embley, T. M., Wait, R., Dobson, G. \& Goodfellow, M. (1987). Fatty acid composition in the classification of Saccharopolyspora hirsuta. FEMS Microbiol Lett 41, 131-136.

Embley, T. M., O’Donnell, A. G., Rostron, J. \& Goodfellow, M. (1988a). Chemotaxonomy of wall type IV actinomycetes which lack mycolic acids. J Gen Microbiol 134, 953-960.

Embley, T. M., Smida, J. \& Stackebrandt, E. (1988b). The phylogeny of mycolate-less wall chemotype IV actinomycetes and description of the new family Pseudonocardiaceae. Syst Appl Microbiol 11, 44-52.

Fox, G. E. \& Stackebrandt, E. (1987). The application of $16 \mathrm{~S}$ rRNA cataloguing and $16 \mathrm{~S}$ rRNA sequencing in bacterial systematics. Methods Microbiol 19, 405-458.

Heuer, H., Krsek, M., Baker, P., Smalla, K. \& Wellington, E. M. H. (1997). Analysis of actinomycete communities by specific amplification of genes encoding $16 \mathrm{~S}$ rRNA and gel-electrophoretic separation in denaturing gradients. Appl Environ Microbiol 63, 3233-3241.

Innis, M. A., Gelfand, D. H., Sninsky, J. J. \& White, T. J. (1990). PCR Protocols. A Guide to Methods and Applications. San Diego: Academic Press.

Korn-Wendisch, F., Rainey, F., Kroppenstedt, R. M., Kempf, A., Majazza, A., Kutzner, H. J. \& Stackebrandt, E. (1995). Thermocrispum gen. nov., a new genus of the order Actinomycetales, and description of Thermocrispum municipale sp. nov. and Thermocrispum agreste sp. nov. Int $J$ Syst Bacteriol 45, 67-77.

Lane, D. J. (1991). 16S/23S rRNA sequencing. In Nucleic Acid Techniques in Bacterial Systematics, pp. 115-175. Edited by E. Stackebrandt \& M. Goodfellow. Chichester: Wiley.

Lathe, R. (1985). Synthetic oligonucleotide probes deduced from amino acid sequence data. Theoretical and practical considerations. $J$ Mol Biol 183, 1-12.

Ludwig, S. \& Schleifer, K. H. (1994). Bacterial phylogeny based on $16 \mathrm{~S}$ and $23 \mathrm{~S}$ rRNA sequence analysis. FEMS Microbiol Rev 15, 155-173.

McVeigh, H. P., Divers, M., Warwick, S., Munro, J. \& Embley, T. M. (1995). Exploration of actinomycetes diversity using ribosomal RNA sequences. In Proceedings of the Ninth International Symposium on the Biology of the Actinomycetes, pp. 253-260. Edited by V. G. Debabov, Y. V. Dudnik \& V. N. Danilenko. Moscow: All-Russia Scientific Research Institute for Genetics and Selection of Industrial Microorganisms.

McVeigh, H. P., Munro, J. \& Embley, T. M. (1996). Molecular evidence for the presence of novel actinomycete lineages in a temperate forest soil. $J$ Ind Microbiol 17, 197-204.

Mehling, A., Wehmeier, U. F. \& Piepersberg, W. (1995). Nucleotide sequences of streptomycete $16 \mathrm{~S}$ ribosomal DNA: towards a specific identification system for streptomycetes using PCR. Microbiology 141, 2139-2147.

Pernodet, J.-L., Boccard, F., Alegre, M.-T., Gagnat, J. \& Guerineau, M. (1989). Organization and nucleotide sequence analysis of a ribosomal RNA gene cluster from Streptomyces ambofaciens. Gene 79, 33-46.

Sanglier, J. J., Haag, H., Huck, T. A. \& Fehr, T. (1993). Novel bioactive compounds from actinomycetes: a short review (1988-1992). Res Microbiol 144, 633-642.

Sasser, M. (1990). Identification of bacteria by gas chromatography of cellular fatty acids. Technical Note 101. Newark, DE: MIDI.

Stackebrandt, E., Witt, D., Kemmerling, C., Kroppenstedt, R. \& Liesack, W. (1991). Designation of streptomycete $16 \mathrm{~S}$ and $23 \mathrm{~S}$ rRNA-based target regions for oligonucleotide probes. Appl Environ Microbiol 57, 1468-1477.

Stackebrandt, E., Liesack, W. \& Witt, D. (1992). Ribosomal RNA and rDNA sequence analyses. Gene 115, 255-260.

Stackebrandt, E., Kroppenstedt, R. M., Jahnke, K.-D., Kemmerling, C. \& Gürtler, H. (1994). Transfer of Streptosporangium virideogriseum (Okuda et al. 1966), Streptosporangium virideogriseum subsp. kofuense (Nonomura and Ohara 1969), and Streptosporangium albidum (Furumai et al. 1968) to Kutzneria gen. nov. as Kutzneria virideogrisea comb. nov., Kutzneria kofuensis comb. nov., and Kutzneria albida comb. nov., respectively, and emendation of the genus Streptosporangium. Int $J$ Syst Bacteriol 44, 265-269.

Stackebrandt, E., Rainey, F. A. \& Ward-Rainey, N. L. (1997). Proposal for a new hierarchic classification system, Actinobacteria classis nov. Int J Syst Bacteriol 47, 479-491.

Stahl, D. A. \& Amann, R. (1991). Development and application of nucleic acid probes. In Nucleic Acid Techniques in Bacterial Systematics, pp. 205-248. Edited by E. Stackebrandt \& M. Goodfellow. Chichester: Wiley.

Takeuchi, M., Tadashi, N. \& Yokota, A. (1992). Taxonomic significance of arabinose in the family Pseudonocardiaceae. Actinomycetologica 6, 79-90.

Thomas, C. A. \& Dancis, B. M. (1973). Ring stability. $J$ Mol Biol 77, 44-55.

Warwick, S., Bowen, T., McVeigh, H. \& Embley, T. M. (1994). A phylogenetic analysis of the family Pseudonocardiaceae and the genera Actinokineospora and Saccharothrix with 16S rRNA sequences and a proposal to combine the genera Amycolata and Pseudonocardia in an emended genus Pseudonocardia. Int J Syst Bacteriol 44, 293-299.

Yassin, A. F., Rainey, F. A., Brzazinka, H., Jahnke, K. D., Weissbrodt, H., Budzikiewicz, H., Stackebrandt, E. \& Schaal, K. P. (1995). Lentzea gen. nov., a new genus of the order Actinomycetales. Int $J$ Syst Bacteriol 45, 357-363.

Yoon, J. H., Kim, H., Kim, S. B., Kim, H. J., Kim, W. Y., Lee, S. T., Goodfellow, M. \& Park, Y. H. (1996). Identification of Saccharomonospora strains by the use of genomic DNA fragments and rRNA gene probes. Int J Syst Bacteriol 46, 502-505. 